\title{
THE FASCINATING IMPLICATIONS OF NEW RESULTS IN GOLD CHEMISTRY
}

\author{
Hubert Schmidbaur \\ Anorganisch-chemisches Institut der Technischen Universität München, \\ Lichtenbergstraße 4, D-8046 Garching, Federal Republic of Germany
}

\begin{abstract}
Chemists today are increasingly fascinated by gold's unique position in the family of elements. In this review, the author looks at important new results emerging from recent research in gold chemistry.
\end{abstract}

\section{Introduction}

In GoldBulletin any discussion of the special position of gold in the family of the noble metals must appear completely superfluous. All those who deal with this element in its various forms every day - be it pure gold as a glittering yellow crystal, as a white-hot melt, or as an almost invisible vapour, or gold as a component of alloys or chemical compounds - know about the remarkable specific properties of the "king of the elements'. But who really have asked often enough the question 'Why?'. And who have persistently followed this scientific challenge until an explanation could be put forward for at least one of the many curious aspects of gold behaviour?

Many have, of course, and yet it has not been until very recently that winds of change have become evident in the thinking of those engaged in the study of gold. First it should be noted that the number of scientists studying gold has increased rapidly and to an unprecedented level. It is impossible to overlook the avalanche, or 'explosive growth', of the literature on gold research and development, and primarily in gold chemistry. And it is especially on the basis of the new thrust in gold chemistry, as the basic science which describes 'matter and its transformations', that our knowledge of the exceptional properties of this element and its compounds has been so greatly extended.

It is difficult to summarize briefly why the unique position of gold in the family of the elements - though clearly recognized very early on - has simply been accepted and not been more of an intellectual challenge to natural scientists. There were only sporadic attempts to explain why gold is the most 'noble' metal with an extreme electrochemical potential [1]. Few scientists also have really paid much notice to the historical discovery of salts with the gold(-I) anion $\mathrm{Au}^{-}$, e.g. in cesium auride $\mathrm{Cs}^{+} \mathrm{Au}^{-}$[2]. For comparison: when some 25 years later salts with $\mathrm{Na}^{-}$anions were presented for the first time [3], this was treated as a true sensation for chemists! The extreme stability of diatomic molecules $\mathrm{Au}_{2}$ in the gas phase was known [4], but received little attention, and the unexpected short lattice constant $\mathrm{Au} \cdots \mathrm{Au}$ in metallic gold, which is in fact shorter than the corresponding $\mathrm{Ag}$... Ag contact in metallic silver [5] was at best considered - like a few other inconsistencies in that area of the Periodic Table - a consequence of 'lanthanide contraction'.

The question of the intriguing colour of gold metal of course has received much attention, but the effect seems to be of what one would nowadays call 'multifactorial origin' (a term originally coined to characterize poorly 
understood phenomena like Waldsterben, or death of the forests), and therefore discussions remained unsettled. It was of little help in this connection that metals like cesium or copper presented similar problems, and the unique position of gold was accepted as being one of many exceptions to a rule.

These and many other puzzling observations associated with gold have been subjected to new scrutiny during the last decade however, when, through the advent of routine structure determination by single crystal $\mathrm{X}$-ray diffraction, a rapidly growing wealth of detailed structural information became available. Not only new oxidation states [6] and coordination numbers [7] were discovered for gold in an aimost unlimited variety of gold compounds, but novel structural phenomena also came to light, mainly regarding unexpected and unprecedented gold...gold contacts [8] absent with other elements and lacking a clear-cut theoretical description. To be specific, structural chemists began to notice that gold atoms showed a strange interatomic attractive force, which, although weak, turned out to determine at least in part molecular configurations and crystal lattices of gold compounds [9]. This phenomenon appeared not only with gold metal in the zero oxidation state $(\mathrm{Au}(0))$ [5], but also in gold clusters with mixed valence characteristics $[10 \mathrm{a}, \mathrm{b}]$, for compounds of the classical $\mathrm{Au}(+\mathrm{I})$ and $\mathrm{Au}(+\mathrm{III})$ oxidation states $[7,8,11]$, and even for the newly discovered $[\mathrm{Au}(+\mathrm{II})]_{2}$ species [12]. In the extremely useful compilations of structural data for gold compounds by Jones which started to appear in Gold Bulletin in the early 1980's, one of the chapters was dedicated to just these phenomena as they became more numerous and more obvious [13].

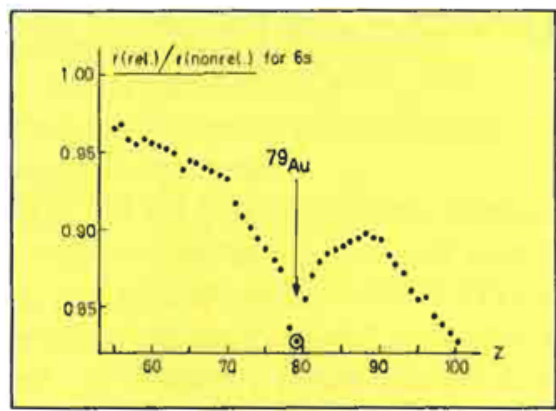

Fig. 1 'Relativistic contraction' $\left(\mathrm{r}_{\mathrm{rel}} / \mathrm{r}_{\text {nonrel }}\right)$ for the $6 \mathrm{~s}$ orbitals of the heavy elements as a function of the atomic number $Z$ [after ref. 14,15 ]. The element gold $(Z=79)$ represents a pronounced local minimum.

The collection of these new observations coincided with a revived interest in gold on the part of theoretical chemists and physicists, and with attempts to reconsider the plethora of unsystematized data in the chemistry of the heaviest elements in the Periodic Table on the basis of relativistic effects [14]. These effects are especially important in the case of those elements with extremely high nuclear charges, since they modify significantly the properties of their valence electrons. It appears that the time-coincidence of these experimental and theoretical moves has been of great significance for recent advances regarding an improved and consistent understanding of gold chemistry. It has become actually possible not only to analyze existing data in the light of this revived theoretical approach, but also to predict new structures and properties [15].

\section{Relativistic Effects and Gold Chemistry}

In the present short review the implications of relativity for gold chemistry [14] can only be briefly summarized. Suffice it to say that electrons in atoms with high atomic numbers under the influence of the increased nuclear point charge reach velocities that approach the velocity of light and therefore have to be treated according to Einstein's theories of relativity. With the term $v_{e} / v_{l}$ (where $v_{e}$ and $v_{l}$ are the velocities of the electron and light, respectively) close to unity, the 'relativistic mass' of the electron is strongly increased, with a consequence also for the orbital radii of these electrons.

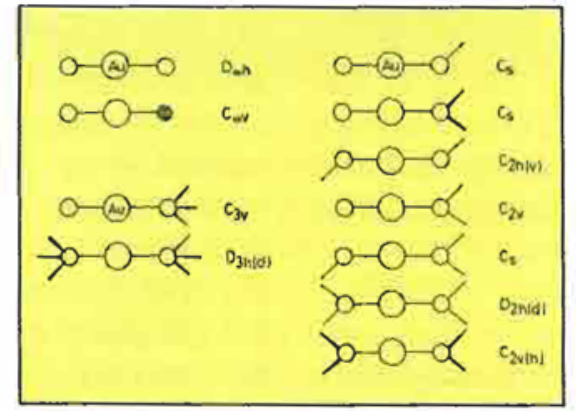

Fig. 2 Standard molecular geometries of (linear) two-coordinate gold(I) complexes and their symmetry characteristics (point groups). The list is not comprehensive, but shows the basic geometries encountered with most simple gold complexes. Free rotation is to be assumed for the gold-to-ligand bonds. The ligands can be neutral, anionic, or cationic.

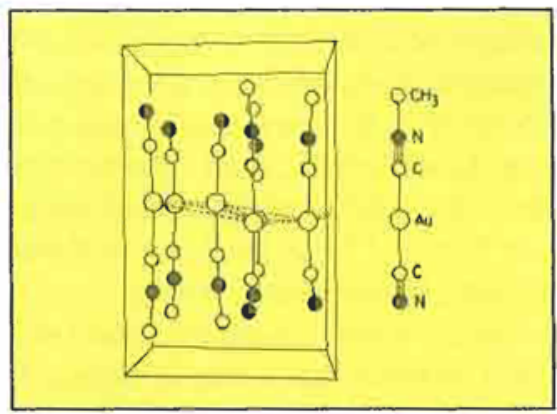

Fig. 3 Crystal packing of methylisocyanide gold(I) cyanide molecules $\mathrm{CH}_{3} \mathrm{NCAuCN}$. The gold atoms are arranged in puckered sheets with short Au...Au contacts [28] 


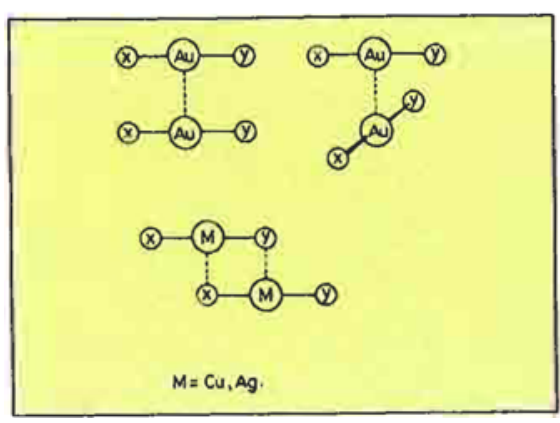

Fig. 4 Scheme of intermolecular interactions between linear two-coordinate gold(I) complexes $X-A u-Y$ and their copper(I) and silver(I) counterparts. $x$ and $y$ are monodentate donor ligands (neutral or anionic).

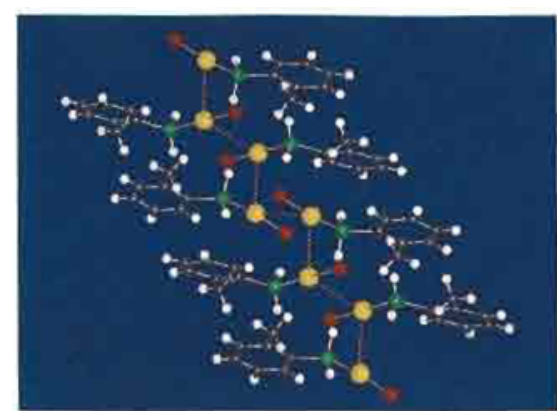

Fig. 5 Crystal structure of [(2-methylphenyl)phosphine]gold(I) bromide (otolylphosphine gold bromide). The molecules are arranged in unidimensional stacks with short Au'*A Au contacts [37].

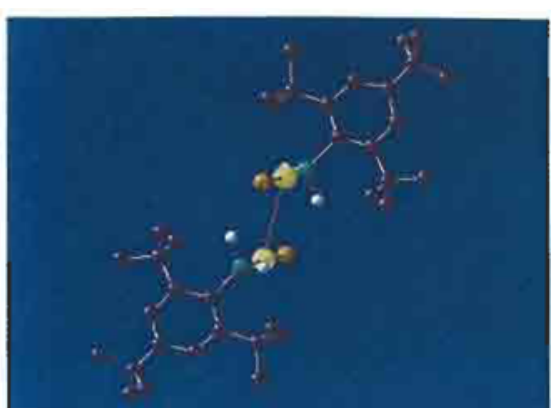

Fig. 6 Pairs of the complex molecules [(2,4,6-tri-t-butyl-phenyl)phosphine]gold(I) chloride in the crystal [38]
In order to directly demonstrate the special position of gold, a plot can be drawn, where the ratio of the relativistic radius of the valence electrons to their nonrelativistic radius is shown as a function of the atomic number (Figure 1). It is clear that this ratio strongly deviates from unity as $Z$ is increased, and that $\mathrm{r}(\mathrm{rel}) / \mathrm{r}$ (non-rel) reaches a pronounced local minimum for the element gold. Thus, without any other special assumptions having to be made, this theoretical approach leads to the conclusion that gold occupies, in fact, a unique position among the elements.

In order to characterize the relativistic effect, it is often split into three (interrelated) 'symptoms':

a) s-orbital and - to a smaller extent - p-orbital contraction,

b) spin-orbit coupling, and

c) d-orbital expansion.

Taken together, these points mean that valence shell electrons of different orbital momentum (s, p, d) are brought much closer together in energy, especially with respect to the gap between the $6 \mathrm{~s}$ and $5 \mathrm{~d}$ states. Recent calculations have shown that through these drastic changes (as compared with the Ag homologue or other neighbouring elements) the block of the so-called $5 \mathrm{~d}^{10}$ 'closed shell' electrons of the $\mathrm{Au}(0)$ or $\mathrm{Au}(+\mathrm{I})$ oxidation states can be 'broken up' and 'mobilized' for chemical bonding [16-18]. The availability of the classical $\mathrm{Au}(+\mathrm{III})$ state of gold as an indication of this phenomenon was recognized very early on [19] and is just one more example, while the pronounced tendency of $\mathrm{Au}(+\mathrm{I})$ to form linear two-coordinate complexes through particularly efficient $\mathrm{s} / \mathrm{p}$ or $\mathrm{s} / \mathrm{d}$ hybridization is another [5-11]. The high electron affinity of $\mathrm{Au}(0)$ with its low-lying 6s state is of course also the basis for the tight bonding in $\mathrm{Au}_{2}$ and the remarkable stability of $\mathrm{Au}^{-}$ anions (above). It would be too euphoric, however, to announce at this stage an 'understanding' of the colour of gold metal!

\section{Aurophilicity}

It is the privilege of review authors to select examples for illustration in a given topic from their own work and present these in the light of their ideas and experience. As already pointed out, one of the most intriguing observations in recent years in the chemistry and structural chemistry of gold has been that of the unprecedented affinity between gold atoms even with 'closed-shell' electronic configurations and equivalent electrical charges. A brief summary of pertinent data is presented below which should exemplify how, from this basis, theory-backed experiments have led to major advances in gold chemistry and contributed to its renewed fascination for chemists. Perhaps prematurely, the effect in question has been baptized with the name 'aurophilicity' as a laboratory colloquialism [20]. Probably this name will not survive time and its loss will not be mourned as the phenomenon becomes widely known and accepted. It may be useful for a while $[21,22]$, however, while related work is in progress, even if it only arouses curiosity [23] and competition.

\section{Unsupported Au ‥Au Contacts between Small Molecules}

Due to its small coordination number of two, gold(I) forms neutral or ionic compounds of the general formula $\mathrm{X}-\mathrm{Au}-\mathrm{Y}$, where the ligands $\mathrm{X}$ and $\mathrm{Y}$ may be the same or different, and neutral or anionic $[5,7,8,11,13,24]$. With small and linear or unbranched chain-like ligands these 


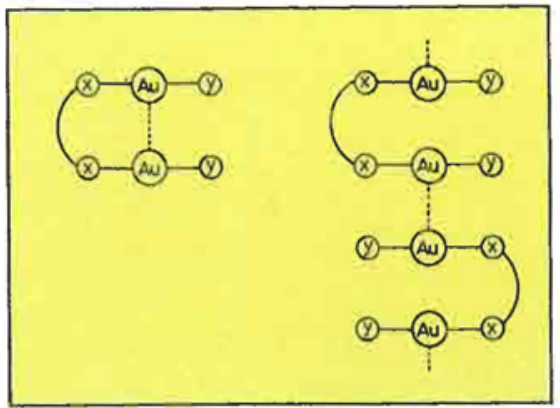

Fig. 7 Scheme of $A u^{\cdots} \cdot A u$ interactions in binuclear gold(I) complexes with bidentate ligands. For the short $\mathrm{Au}$-..Au contacts there is a choice between intra- or intermolecular approach.

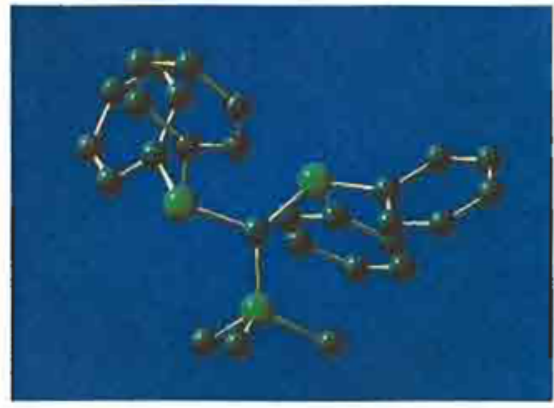

Fig. 8a Molecular structure of the uncomplexed ligand trimethylphosphonium bis(diphenylphosphino)methylide, $\left(\mathrm{CH}_{3}\right)_{3} \mathrm{P}=\mathrm{C}\left[\mathrm{P}\left(\mathrm{C}_{6} \mathrm{H}_{5}\right)_{2}\right]_{2}$, in the crystal. The phosphine donor functions are in a cis/trans orientation $(\mathrm{E} / \mathrm{Z})$ relative to the ylidic $\mathrm{P}=\mathrm{C}$ bond [54].

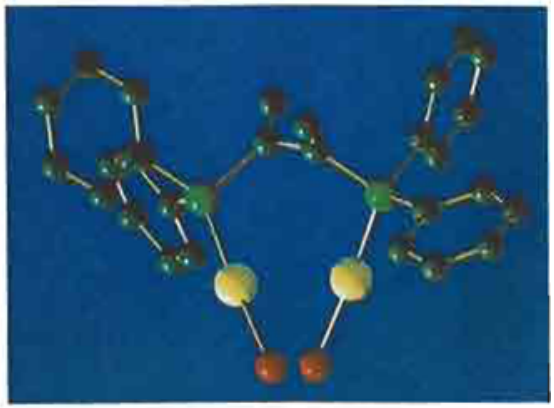

Fig. 9 Molecular structure of the 1:2 complex of 2,3-bis-(diphenylphosphino)1,3-butadiene with $\mathrm{AuCl}$ in the crystal. The diphosphine approaches the s-cis conformation (which is not the ground state geometry of the free ligand) and allows close $\mathrm{Au} \cdots \mathrm{Au}$ contacts [55].

complexes have linear or snake-like molecular shapes, while with substituents pointing away from the molecular axis, the complexes can became flat and finally tree

atoms of the strictly linear molecules form puckered planes, from which the carbonyl and chloride ligands and tree-root shaped $[8,11,13,24]$. Some are symmetrical tops or obey even higher molecular symmetry (Figure 2).

On careful inspection of the crystal structures of representatives of this family of complexes [13], it becomes apparent that virtually all of them - steric requirements permitting - are packed or arranged in such a way that the gold(I) atoms are as close to each other as possible. As a rule of thumb, the Au atoms are found in pairs, rings, chains or layers with interatomic distances of 3.00 $\pm 0.25 \AA$. While the upper end of this range $(3.25 \AA)$ is approaching the van der Waals contact distances of smaller atoms and is indicative of only weak bonding, this is certainly not true for the lower end $(2.75 \AA)$, because this value is already well below the $\mathrm{Au} \cdots \mathrm{Au}$ distance in metallic gold and within the range of the experimental values for true $\mathrm{Au}-\mathrm{Au}$ bonding, as between two $\mathrm{Au}$ (II) centres $\left(d^{9}\right)$ in the diatomic unit $\mathrm{Au}_{2}{ }^{4+}$, for example $[6,12,25]$, or in mixedvalent gold clusters with multi-centre bonding characteristics $[10,26]$.

A case in point is the layer structure of $(\mathrm{OC}) \mathrm{AuCl}$, where the gold

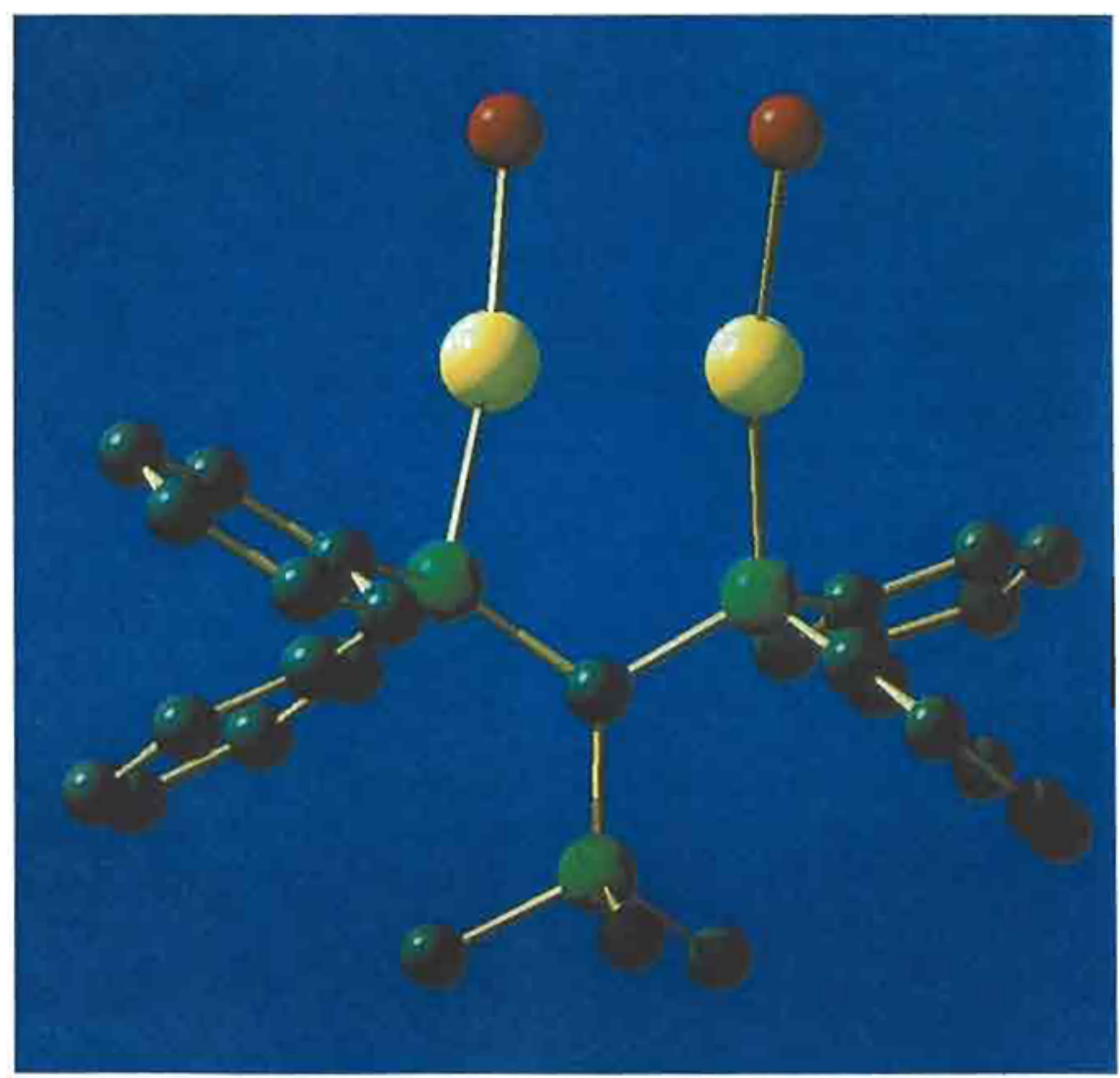

Fig. 8b Molecular structure of the 1:2 complex of the ligand in Fig. 8a with AuCl. Through a $\mathrm{P}-\mathrm{C}$ single bond rotation of one of the ligand arms $\left[\mathrm{C}-\mathrm{P}\left(\mathrm{C}_{6} \mathrm{H}_{5}\right)_{2}\right]$ the gold atoms have been brought into close contact. The ligand now has the trans/trans (E/E) conformation, which is higher in energy for the free ligand [54]. 


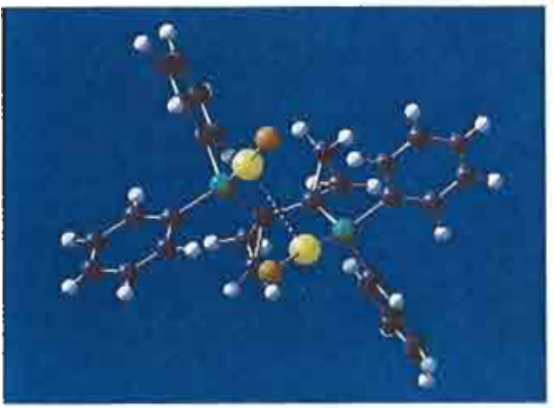

Fig. 10 Molecular structure of the 1:2 complex of 2,3-bis-(diphenylphosphino)bicyclopropyl with $\mathrm{AuCl}$ in the crystal. Through adoption of a near-cis conformation, not observed with the free ligand, $\mathrm{Au} \cdots \mathrm{Au}$ interactions are established [56].

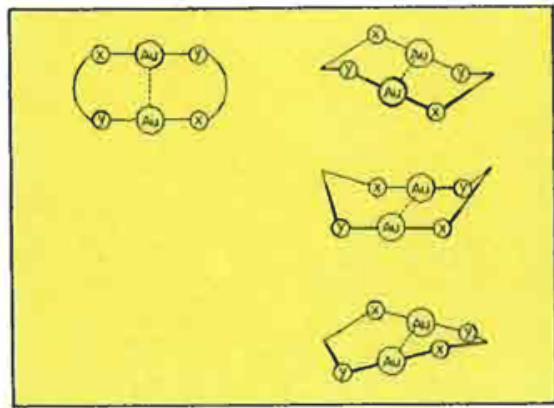

Fig. 11 Scheme of transannular Au…Au contacts in cyclic dinuclear Au(1) complexes in the chair, boat, and twist conformations, respectively

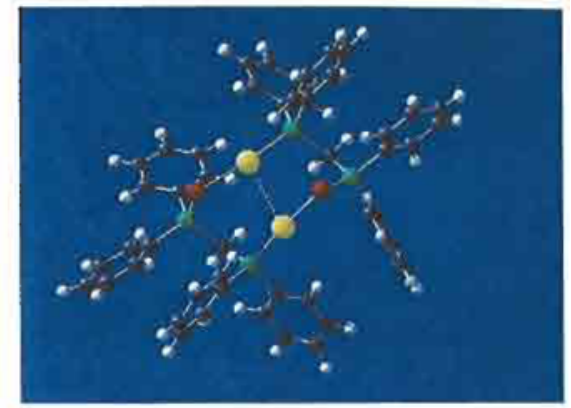

Fig. 12 Molecular structure of the dication $\left[\left(\mathrm{C}_{6} \mathrm{H}_{5}\right)_{2} \mathrm{PCH}_{2} \mathrm{P}\left(\mathrm{C}_{6} \mathrm{H}_{5}\right)_{2} \mathrm{SeAu}_{2}{ }^{2+}\right.$ in crystals of the perchlorate salt. The ten-membered ring is folded such that transannular Au'.AAu contacts are possible [75]. situation is found in crystals of the complex $\mathrm{H}_{3} \mathrm{CNCA}$ $\mathrm{uCN}$ with its linear chain of non-hydrogen atoms [28]. It is only for the methyl hydrogen atoms that the molecules are threefold symmetrical tops (point group $\mathrm{C}_{3 \mathrm{v}}$, Figure 3). Again, the gold atoms form layers, but with somewhat longer $\mathrm{Au} \cdots \mathrm{Au}$ contacts than in $(\mathrm{OC}) \mathrm{AuCl}$. It appears that in cases where the ligands $X$ and $Y$ have no or negligible steric demand perpendicular to the molecular axis, the gold-gold contacts perpendicular to the molecular axis determine the crystal packing of these molecules. This is surprising, since in the structural chemistry of coordination compounds of other metals, the metal(molecule 1)-ligand(molecule 2) interactions seem as a rule to dominate molecular packing. This is particularly true in the complexes of copper(I) or silver(I) halides, where metal-halogen contacts are the dominating structural features in four-membered rings, cubes, stairs and other forms (Figure 4), [29,30].

In cases where the steric requirements of the ligands $X$ and $Y$ are greater, the packing of the molecules obviously becomes more difficult and a chain-like array is preferred. This is true for compounds like $\left(\mathrm{C}_{4} \mathrm{H}_{8} \mathrm{~S}\right) \mathrm{AuBr}$, with a rather flat tetrahydrothiophene ligand [31], which crystallizes as $\left.\left[\mathrm{C}_{4} \mathrm{H}_{8} \mathrm{~S}\right)_{2} \mathrm{Au}\right]+\mathrm{AuBr}_{2}$ with $\mathrm{Au} \cdots \mathrm{Au}$ contacts between cations and anions as they are stacked. Similar structures are found not only for other sulfur ligands like $\mathrm{PhSCH}_{2} \mathrm{CH}_{2} \mathrm{SPh}$ [32] or dibenzylsulfide [33], but also for adducts of pyridine, isopropylamine, and piperine [34-36]. Some of these examples may not develop infinite one-dimensional chains, but have these broken up into finite oligomers, e.g. cyclic or open-chain tetramers [13].

Very recent work has revealed a chain-like structure also for a complex of $\mathrm{AuCl}$ with a (flat) primary phosphine, $\mathrm{RPH}_{2} \cdot \mathrm{AuCl},(\mathrm{R}=\mathrm{o}$-tol $)$, but with a peculiar folding of the string of gold atoms (Figure 5), [37]. A bigger group $\left(2,4,6-\mathrm{C}_{6} \mathrm{H}_{3} \mathrm{BBu}_{3}\right)$ reduces the packing to pairs, in which the pair of gold atoms represents a core unit [38]. With secondary or even tertiary phosphines, the interactions are reduced further, but dimers with parallel or perpendicular $\mathrm{L}-\mathrm{Au}-\mathrm{X}$ axes can still be found [39-41], until only monomers are left, e.g. with $\mathbf{R}_{3} P$ ligands, where $\mathrm{R}=\mathrm{C}_{6} \mathrm{H}_{5}$ (Figure 6), [42].

A related, but nevertheless peculiar example was reported very recently in the form of a compound of the composition $\left(\mathrm{MePh}_{2} \mathrm{P}\right) \mathrm{AuCl} \cdot\left(\mathrm{MePh}_{2} \mathrm{P}\right) \mathrm{AuSiPh}_{3}$, which turned out to be an ionic complex $\left[\left(\mathrm{MePh}_{2} \mathrm{P}\right)_{2} \mathrm{Au}\right]^{+}$ $[\mathrm{ClAuSiPh}]^{-}$, but with the axes of the cation and the anion in a perpendicular alignment and with the two $\mathrm{Au}$ atoms in close proximity $(2.981 \AA)$. From this structure the species can be classified as a dinuclear $\mathrm{Au}$... Au bonded aggregate [43].

To mention finally another fully inorganic 'classic', the structure of sodium gold(I) bis(thiosulfate) $\mathrm{Na}_{3}\left[\mathrm{Au}\left(\mathrm{S}_{2} \mathrm{O}_{3}\right)_{2}\right]$ is to be recalled, where the triply charged anions (!) form pairs with the S-Au-S axes perpendicular at an $\mathrm{Au}$...Au distance of as low as $3.24 \AA$ [44]. By contrast, the silver analogue forms chains with sulfur bridges between the $\mathrm{Ag}(\mathrm{I})$ centres! [45].

There is no evidence available at present that these low molecular weight aggregates or small parts of the polymer chains survive in solution. It appears that solvation of individual complex units with solvent molecules is stronger than the intermolecular forces originating from the $\mathrm{Au} \cdots \mathrm{Au}$ contacts. This places the latter in the category of 'weak forces' with associated energies typically in the order of 5 to $15 \mathrm{kcal} / \mathrm{mole}$. This estimate has later been confirmed experimentally for favourable cases, where suitable physical methods could be applied (see below). 


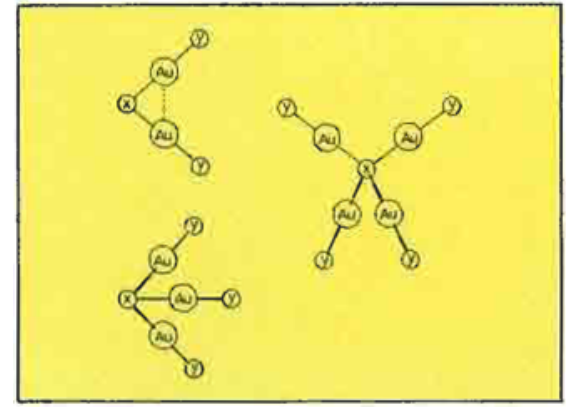

Fig. 13 Scheme of single-atom bridged di-, tri-, and tetranuclear gold(I) complexes. $X$ can be $\mathrm{Cl}, \mathrm{S} ; \mathrm{O}, \mathrm{S}, \mathrm{Se} ; \mathrm{N}, \mathrm{P}$, respectively; $Y$ in most cases represents triphenylphosphine.

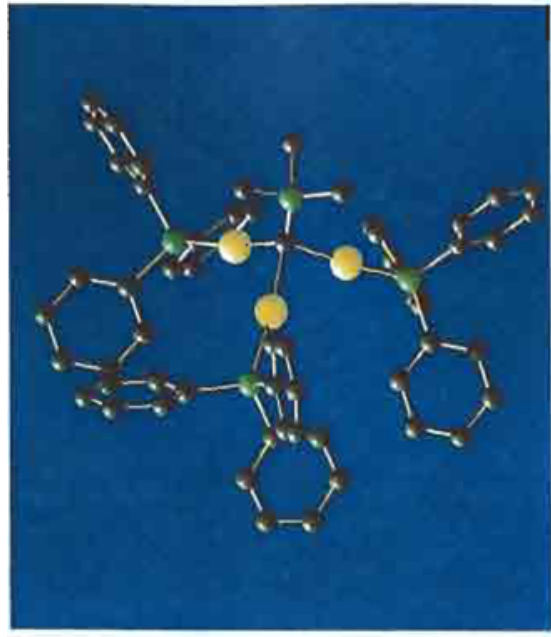

Fig. 14 Molecular structure of the cation $\left(\mathrm{CH}_{3}\right)_{3} \mathrm{PC}-\left[\mathrm{AuP}\left(\mathrm{C}_{6} \mathrm{H}_{5}\right)_{3}\right] 3^{+}$in the crystal of the chloride salt [93]

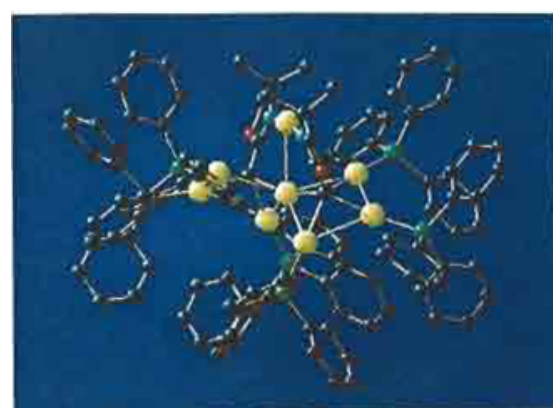

Fig. 15 Molecular structure of the dication $\left\{\mathrm{OxC}\left[\mathrm{AuP}\left(\mathrm{C}_{6} \mathrm{H}_{5}\right) 3\right] \mathbf{3 A u}_{3} \mathbf{2}^{2+}\right.$ (with $O x$ representing the oxazalinyl group) in the crystal of the trimethyldifluorosilicate salt. The two symmetry-related carbon atoms attached to the $O x$ rings are each bonded to four gold atoms. These carbon atoms are thus pentacoordinate and positioned in the centre of corner-sharing tetragonal pyramids [94].

\section{Ligand-supported Au $\cdots$ Au Contacts in Non-Cyclic Polynuclear Complexes}

Entropy considerations predict that the presence of a bridging or chelating ligand should greatly facilitate intramolecular metal-metal contacts in di- or poly-nuclear complexes. This is borne out by experiments, but many of the structural features encountered in such cases were for some time solely ascribed to the forcing conditions of the ligand and not to any significant $\mathrm{Au}$... Au attraction. These 'forcing conditions' sometimes also obscured the $\mathrm{Au}$... Au interactions by preventing the close approach for reasons associated with the ligand geometry. This is true, for example, for the $1: 2$ complex of $\mathrm{Ph}_{2} \mathrm{PCH}_{2} \mathrm{PPh}_{2}$ (dppm) with AuCl [46], where the $\mathrm{Au}$...Au distance is found at $3.245 \AA$, almost $10 \%$ longer than the average value detected in strainfree complexes.

A second phenomenon can be equally misleading: In the crystal, intermolecular contacts are often preferred over intramolecular contacts, and the former either can be more easily overlooked or taken less 'seriously' by the investigators. It is thus only the evaluation of the complete three-dimensional system which tells the true story. To illustrate this point, the formulae in Figure 7 can be used to systematize, for example, the complexes of $\mathrm{AuCl}$ with difunctional phosphines showing major or only subtle differences in their basic skeleton [47-52]. Again, the differences as compared to related silver complexes should be noted [53].
Of special relevance are model complexes where the conformational changes of the ligands occurring upon metal complexation are associated with energy barriers in a region convenient for detection by spectroscopic techniques.

Three examples have been investigated more closely, and the results have shown a very satisfactory agreement regarding the value obtained for the alleged $\mathrm{Au}$.. Au attraction. A series of tri-organophosphoniumbis(diphenylphosphino)methylides [54] and the di-tertiary phosphines derived from butadiene [55] and bicyclopropyl [56] adopt - as free ligands - ground state conformations which do not allow metal-metal contacts in their dinuclear complexes with AuCl. The former have a syn/anti conformation relative to the ylidic function (Figure 8a), and the latter two adopt the single-trans conformation (butadiene) or a form close to this extreme (bicyclopropyl) [57]. In 1:1 complexes, these conformations are retained, which is proof that phosphine coordination in principle is not necessarily associated with conformational changes. In the $2: 1 \mathrm{com}$ plexes, however, such a change, which brings the gold atoms into proximity, is consistently observed (Figures $8 b, 9,10)$, [54-56].

Since the energy differences between the syn/anti (E/Z) or s-cis/s-trans conformations are known, it is possible to make reliable estimations of the $\mathrm{Au}$... Au attraction forces which overcome the directional forces operative in the ligand. It is obvious from the formulae also, that the conformations adopted in the complexes contradict electrostatic reasoning, since units of equivalent charge or polarization are brought together - an 
unknown phenomenon for standard situations with other dinuclear complexes of closed-shell metal atoms. The values arrived at in the three types of complexes are in the order of $6-8 \mathrm{kcal} / \mathrm{mole}$ [54-56]. This result confirms the classification of the $\mathrm{Au}$...Au attraction as a 'weak force', compared best in magnitude perhaps with hydrogen bonding, or with solvation in weakly polar media. It also explains, of course, why this attraction is often overruled in a competition with stronger forces, and may even remain completely obscured and go unnoticed. This does not mean, however, that this force is unimportant: the enormous role played by hydrogen bonding or solvation in chemical systems, last not least in biological systems, is a good illustration of how a large number of weak forces can often become the decisive influence.

\section{Au ...Au Contacts in Cyclic Complexes}

With one or more gold(I) centres present as members of ring systems, the linear array of ligands at these metal centres induces 'stretched' configurations, which are not easily accommodated in small rings. It is for this reason that metallocyclic chemistry of gold(I) starts with eight-membered rings. This ring size is most abundant in gold(I) chemistry, and it is easily recognized that it corresponds to an 'elongated cyclohexane' structure (if saturated), and to an 'elongated benzene' structure (if double bonding is involved). As with cyclohexane, the (saturated) rings may adopt chair, boat, or twist conformations, and in fact all three of them have been detected in the structural chemistry of gold(I), (Figure 11).

The most common chair conformation and the (less well represented undistorted) boat conformation have two $\mathrm{X}-\mathrm{Au}-\mathrm{Y}$ axes $(\mathrm{X}, \mathrm{Y}=$ ligand donor element) running parallel to each other, while in the twist conformation these axes form small angles, but with the line connecting the two gold atom as their closest approach [58-65]. The 'elongated cyclohexane' structure is found with di-phosphinomethanes, phosphonium bis(methylides) ('ylides'), di-thio-phosphates and di-thio-phosphinates or -phosphonates [13], and even inorganic ligands like tetra-thiotungstate, $\mathrm{WS}_{4}{ }^{2-}[66]$, or tetrathiostannate $\mathrm{SnS}_{4}$ 4- [67].

The 'elongated benzene' structure (sometimes twisted) is typically found with dithio-carbamates [13], (thio)carboxylates [68], $\alpha$-functional pyridines [69], diphosphino-methanides $[70,71]$, and related ligands, all with a formally $\mathrm{sp}^{2}$ hybridized bridging atom.

For a large number of structures of these eightmembered rings, the trans-annular $\mathrm{Au} \cdots \mathrm{Au}$ contacts are found consistently at the 'magic' distance of 3.00 $\pm 0.25 \AA$, irrespective of the ring conformation (chair, boat, twist, planar) [13].

It remains a matter for debate, however, as to whether these contacts are solely determined by the ligand 'bite', or whether they are also a consequence of aurophilicity. Even the observation that the $\mathrm{X}-\mathrm{Au}-\mathrm{Y}$ axes are often not linear, but show an angle smaller than 180 degrees in such an orientation that the metal atoms come closer together, is only an indication, but no final proof. It should also be pointed out that a large variety of 1,3-difunctional ligands with donor and bridging atoms of very different nature (and size) can be applied without bringing about any major changes in the Au...A Au contact, which again is at least consistent with the assumption of a conformation-determining influence of $\mathrm{Au} \cdots \mathrm{Au}$ contacts.

For many of the cyclic complexes a strong visible luminescence has been observed on UV irradiation [7274]. These experiments and some studies of the UV/VIS spectra of the compounds have prompted theoretical studies aiming at a correlation between $\mathrm{Au}$ '. Au bonding and spectral behaviour. The first results have been published and more material will probably be available very soon [74].

The situation is more comforting from this point of view as the ring size is increased beyond eight. Tenmembered rings are known to be much more flexible, and it is therefore surprising that several recent structures [73-76] where two gold(I) centres are in 1,6 positions again clearly show the transannular approach to ca. $3.00 \AA$ which is so well documented for eightmembered rings. In all cases the donor atoms $E$ and the ring folding are quite different, but the resulting $\mathrm{Au} \cdots \mathrm{Au}$ contacts are equivalent (Figure 12). Probably many more of these peculiar large-ring conformations will be found, but the number of examples is still very limited [13].

\section{Single-atom Bridged Polynuclear Gold Complexes}

If two metals are bridged by a single atom of a different element, their distance will only exceed the sum of their van der Waals radii if the valence angle at the bridging element is very large (linear for an $180^{\circ}$ angle). Already with standard tetrahedral angles, to mention just a very common example, this distance will be much shorter, and the small angles present between atoms at the corners of polyhedra with more than four vertices will bring these metals even further together. 


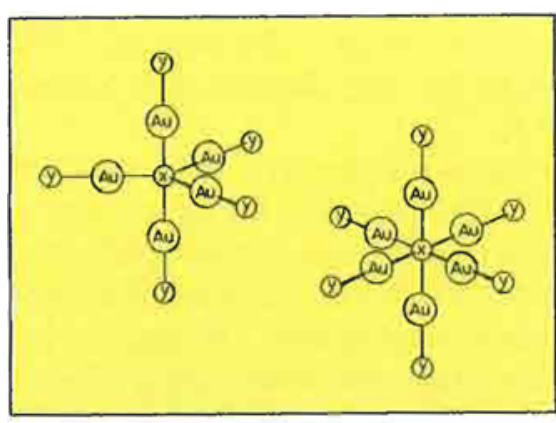

Fig. 16 Scheme of polyaurated species with five and six gold atoms attached to a central element $x$. In fully established examples $x$ represents $C$ or $N$, and $y$ stands for triphenylphosphine $[95,96$, 100]. (See also Figs. 17, 18).

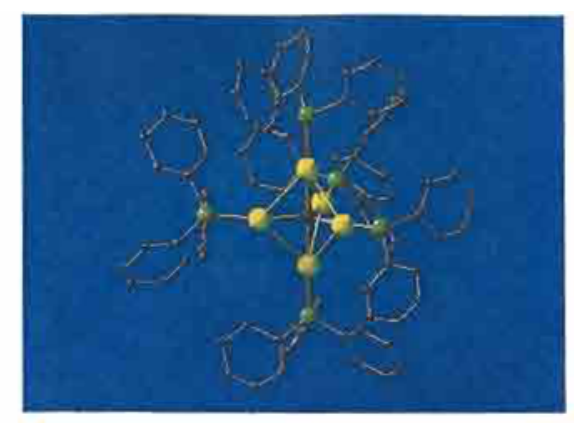

Fig. 17 Molecular structure of the monocation $\left\{\mathrm{C}\left[\mathrm{AuP}\left(\mathrm{C}_{6} \mathrm{H}_{5}\right) 3\right] 5\right\}+$ in the crystal of the tetrafluoroborate salt $[95$

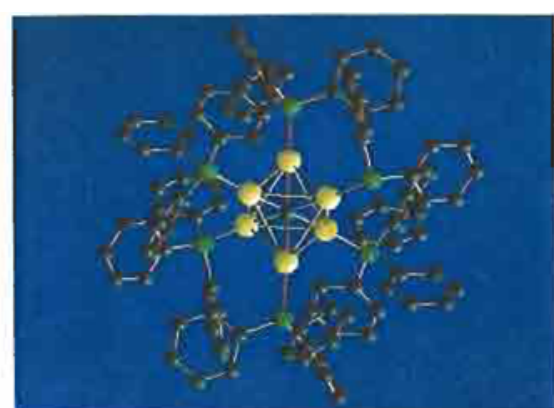

Fig. 18 Molecular structure of the dication $\left\{\mathrm{C}\left[\mathrm{AuP}\left(\mathrm{C}_{6} \mathrm{H}_{5}\right) 3\right] 6\right\}^{2+}$ in the crystal of the $\mathrm{CH}_{3} \mathrm{OBF} 3^{-}$salt [96]
If aurophilicity is accepted as a common effect for gold(I), this reasoning must mean that gold atoms should show a pronounced tendency to cluster around a given central element, since all the peripheral gold contacts in such a (centred) cluster should contribute to the overall stability.

And in fact, a careful re-evaluation of the literature [13] shows many examples for this phenomenon. There are the early observations that treatment of aryl- or ferrocenyl-gold-phosphine complexes with tetrafluoroboric acid gives complexes where two gold atoms are accommodated at a common carbon atom of a benzene or cyclopentadienyl ring, respectively [77-80]. Less striking (through the analogy with alkali- and copper-aryls), but still pertinent, is the aggregation of mesitylgold(I) to give pentamers with two gold atoms associated with one of the arene carbon atoms [81].

These results are particularly intriguing as the ring aromaticity clearly is abandoned in order to secure addition of a second gold(I) centre to a carbon atom! Two gold atoms at a common non-arene carbon atom were soon detected also in ylidic species. No comment would be necessary here, were it not that the Au-C-Au angles are found to be smaller than the tetrahedral value [82-84]. Equally unexpected were the readiness of formation of triauro-oxonium, -sulfonium, and -selenonium salts, and the molecular structures of these products [76a,85-89]: in all cases, steep pyramids $\left[\mathrm{E}(\mathrm{AuL})_{3}\right]^{+}$ with $E=O, S, S e$, and short $\mathrm{Au} \cdots A$ Au contacts were detected, and these units are further dimerized to allow for even more $\mathrm{Au} \cdots \mathrm{Au}$ intercationic interactions. These findings were quickly followed by the synthesis and characterization not only of tetraauro-ammonium and -phosphonium salts, $\left[\mathrm{N}(\mathrm{AuL})_{4}\right]^{+}$and $\left[\mathrm{P}(\mathrm{AuL})_{4}\right]^{+},(\mathrm{L}=$ $\left.\mathrm{PPh}_{3}\right)$, respectively $[90,91]$, but also by diaurochloronium salts (Figure 13), [92].
While the majority of these results may have been serendipitous, more recent work was undertaken in order deliberately to find more examples for an aurophilicity clustering phenomenon. With the stage set by previous studies, some of the experiments to be carried out now seemed obvious and straightforward, and these endeavours were therefore successful very quickly. A whole series of novel species have been obtained, with the main focus on carbon-centred polyauriomethanes: in the course of the synthesis of triauriomethanes $\mathrm{RC}(\mathrm{AuL})_{3}$ (Figure 14), [93], the generation of the first tetraauriomethanium cations $\left[\mathrm{RC}(\mathrm{AuL})_{4}\right]^{+}$was observed (Figure 15), [94], and these experiments led to the discovery of the homoleptic penta- and hexa-auriomethanonium cations, $\left[\mathrm{C}(\mathrm{AuL})_{5}\right]^{+}$and $\left[\mathrm{C}(\mathrm{AuL})_{6}\right]^{2+}$ (Figure 16), $[95,96]$.

It thus appears that aurophilicity in tri- and tetra-auriomethanes is so strong that further $\mathrm{LAu}^{+}$cations are accommodated at the central carbon atom to give trigonal-bipyramidal and finally octahedral structures. The details of these were determined by spectroscopic and single crystal X-ray diffraction studies (Figures 17, 18), [93-96].

Theoretical studies have shown that structure and bonding in these new compounds can be rationalized by quantum-chemical treatment of model systems with simplified ligands, and in this context it proved particularly important to include relativistic effects in order to account for the observed stability of the novel species [16].

Last but not least, it emerged that the new experimental findings helped to clarify a few previous inconsistencies in the literature [97-99], and that one of the most spectacular species, the $\left[\mathrm{C}(\mathrm{AuL})_{6}\right]^{2+}$ cation, had already been predicted [ $16 \mathrm{c}]$ as a result of quantum-chemical studies of non-centred and centred gold clusters. 
It is extremely gratifying that the chemistry of gold has thus reached a sound platform regarding gold...gold interactions and gold clustering, from which research can now set out in many new directions. Projects currently in progress in several laboratories show many signs of this. Of these, the synthesis of a pentaauroammonium di-cation $\left[\mathrm{N}(\mathrm{AuL})_{5}\right]^{2+}$ is probably most spectacular (!) [100], closely followed by the first indications that gold(III) can show equally exciting structural features [101], and that the neighbouring metals platinum, mercury, and thallium [102-104], and the homologue silver [105], can be integrated into the gold aggregates. The chemistry of other transition metal clusters containing gold atoms has been an active field for some time already and continues to flourish $[106,107]$. Solid state chemistry witnesses a similar development. Many unexplained features in the results of classical studies have now been followed up from a different point of view and complemented by corroborative findings. As this area has only recently been reviewed, it may suffice here to just mention this point very briefly [108].

Both the solid state chemistry and the molecular and coordination chemistry of gold outlined above will have a bearing on present and future usage and application of gold and its compounds [109]. Too little of this may be immediately obvious, but scientists at least are lucky in that this does not really detract from the fascination their research field is holding for them.

\section{Acknowledgements}

The author is indebted to many colleagues for helpful discussions, in particular Professors J.P. Fackler, R. Hoffmann, P.G. Jones, D.M.P. Mingos, P. Pyykkö, and $R$. Uson, who have contributed so much to gold chemistry in theory or experiment, but also to his students for their enthusiastic cooperation. Support of the work carried out in the Munich laboratories by Deutsche Forschungsgemeinschaft, Fonds der Chemischen Industrie, Degussa AG, W.C. Heraeus GmbH, and Hoechst AG is gratefully acknowledged.

\section{References}

1 N.N. Greenwood, A. Earnshaw 'Chemistry of the Elements', Pergamon, Oxford 1984, 1364 ff

2 E. Zintl, J. Goubeau, W.Z. Dullenkopf, Z. Phys. Chem. 1931, A 154 1; A.H. Sommer, Nature (London) 1943, 152, 215; W.J. Peer, J.J. Lagowski, J. Amer. Chem. Soc., 1978, 100, 6260

3 J.L. Dye, Angew. Chem., 1979, 91, 613; Angew. Chem. Int. Ed. Engl., 1979, 18, 587

4 T.G. Spiro, Progr. Inorg. Chem., 1970, 11, 1; K.A. Gingerich, J. Cryst. Growth, 1971, 9, 31; J. Kordis, K.A. Gingerich, R.J. Seyse, J. Chem. Phys., 1974, 61, 5114

5 A.F. Wells, 'Structural Inorganic Chemistry', 5th Ed., Clarendon Press, Oxford, 1987

6 H. Schmidbaur, K.C. Dash, Adv. Inorg. Chem. Radiochem., 1982, 25, 239

7 R.J. Puddephatt in 'Comprehensive Coordination Chemistry' (G. Wilkinson, R.D. Gillard, J.A. McLeverty, eds.) Vol. 5, Pergamon, Oxford 1987, and in 'Comprehensive Organometallic Chemistry' (G. Wilkinson, F.G.A. Stone, E.W. Abel, editors), Vol. 2, Pergamon, Oxford, 1985

8 R.J. Puddephatt 'The Chemistry of Gold', Elsevier, Amsterdam, 1978

9 H. Schmidbaur in 'Gold 100', Vol. 3, ASIMM, Johannesburg, 1986

10 a) D.M.P. Mingos, Gold Bull., 1984, 17, 5;

b) J.Chem. Soc. Dalton Trans., 1163, 1976

c) K.P. Hall, D.M.P. Mingos, Progr. Inorg. Chem., $1984,32,237$

$11 \mathrm{H}$. Schmidbaur 'Organogold Compounds', Gmelin Handbook of Inorganic Chemistry, Springer-Verlag, Berlin, 1980

12 H. Schmidbaur, A. Wohlleben, F. Wagner, D.F. van der Vondel, G.P. van der Kelen, Chem. Ber, 1977, 110, 2758; H. Schmidbaur, J.R. Mandl, A. Frank, G. Huttner, ibid. 1976, 109, 466

13 a) P.G. Jones, Gold Bull., 1981, 14, 102 and 159; b) ibid., 1983, 16, 114;

c) ibid., 1986, 19, 46

14 P. Pyykkö, J.P. Desclaux, Accounts Chem. Res., 1979, 12, 276; K.S. Pitzer, ibid., 1979, 12, 271, and literature therein

15 P. Pyykkö, Chem. Rev., 1988, 88, 563, and refs. therein

16 N. Rösch, A. Görling, D.E. Ellis, H. Schmidbaur, Angew. Chem., 1989, 101, 1410; Angew. Chem. Int. Ed. Engl., 1989, 28, 1357

17 Y. Jiang, S. Alvarez, R. Hoffmann, Inorg. Chem., 1985, 24, 749

18 K.M. Merz, R. Hoffmann, Inorg. Chem., 1988, 27, 2120; P. K. Mehrotra, R. Hoffmann, ibid., 1978, 17, 2187. A. Dedieu, R. Hoffmann, J. Amer. Chem. Soc. 1978, 100, 2074

19 Ref. 1, p. 1369 
20 F. Scherbaum, A. Grohmann, B. Huber, C. Krüger, H. Schmidbaur, Angew. Chem., 1988, 100, 1602; Angew. Chem. Int. Ed. Engl., 1988, 27, 1544

21 Chem. Eng. News, 1988, Dec. 5; New Scientist 1989, July 8, p. 39

22 W.S. Rapson, Gold Bull., 1989, 22, 19

23 R. Hoffmann, American Scientist, 1989, 77, 330

24 H. Schmidbaur, Angew. Chem., 1976, 88, 830; Angew. Chem. Int. Ed. Engl., 1976, 15, 728

25 Ref. 13c, p. 55, and numerous papers from the laboratory of J.P. Fackler

26 Ref. 13a, p. 105; Ref. 13b, p. 115

27 P.G. Jones, Z. Naturforsch. B, 1982, 37, 823

28 S. Esperas, Acta Chem. Scand., 1976, A30, 527

29 A.A.M. Aly, U. Schubert, D. Neugebauer, H. Schmidbaur, Angew. Chem., 1978, 90, 125; Angew. Chem. Int. Ed. Engl., 1978, 17, 125; H. Schmidbaur, A.A.M. Aly, U. Schubert, ibid., 1978, 90, 905; 1978, 17, 846

30 Y. Inoguchi, B. Milewski-Mahrla, D. Neugebauer, G.P. Jones, H. Schmidbaur, Chem. Ber., 1983, 116, 1487 , and ref. therein

31 S. Ahrland, B. Noren, A. Oskarsson, Acta Chem. Scand. $1985,24,1330$

32 M.G.B. Drew, M.J. Riedl, J. Chem. Soc. Dalton Trans., 1973, 52

33 J. Strähle, W. Hiller, W. Conzelmann, Z. Naturforsch., $1984,39,538$

34 H.-N. Adams, W. Hiller, J. Strähle, Z. Anorg. Allg. Chem., 1982, 485, 81; W. Conzelmann, W. Hiller, J. Strähle, ibid., 1984, 512, 169

35 P.W.R. Corfield, H.M.M. Shearer, Acta Crystallogr., $1967,23,156$

36 J.J. Guy, P.G. Jones, M.J. Mays, G.M. Sheldrick, J. Chem. Soc. Dalton Trans., 1977, 8

37 H. Schmidbaur, G. Weidenhiller, O. Steigelmann, G. Müller, Chem. Ber, in press

38 H. Schmidbaur, G. Weidenhiller, O. Steigelmann, G. Müller, Z. Naturforsch., B, i. pr.

39 H. Schmidbaur, A.A.M. Aly, Z. Naturforsch., B, 1979, 34, 23

40 D.B. Dyson, R.V. Parish, C.A. McAuliffe, R.G. Pritchard, R. Fields, B. Beagley, J. Chem. Soc. Dalton Trans., 1989, 907

41 G.J. Arai, Recl. Trav. Chim. Pays-Bas, 1962, 81, 307

42 S. Ahrland, K. Dreisch, B. Noren, A. Oskarsson, Acta Chem. Scand., 1987, A 41, 173

43 J. Meyer, H. Piana, H. Wagner, U. Schubert, Chem. Ber., in press

44 R.F. Baggio, S. Baggio, J. Inorg. Nucl. Chem., 1973, 35, 3191; H. Ruben, A. Zalkin, M.O. Faltens, D.H. Templeton, Inorg. Chem., 1974, 13, 1836

45 Gmelin Handbuch d. Anorg. Chem., 8. Aufl., Silber B3, Verlag Chemie, Weinheim, 1973, 117
46 H. Schmidbaur, A. Wohlleben, F. Wagner, O. Orama, G. Huttner, Chem. Ber, 1977, 110, 1748

47 H. Schmidbaur, R. Herr, T. Pollok, G. Reber, A. Schier, G. Müller, Phosphorus \& Sulfur, 1987, 30, 273, H. Schmidbaur, A. Schier, G. Reber, G. Müller, Inorg. Chim. Acta, 1988, 147, 143

48 H. Schmidbaur, T. Pollok, G. Reber, G. Müller, Chem. Ber., 1988, 121, 1345

49 P.A. Bates, J.M. Waters, Inorg. Chim. Acta, 1985, 98 , 125; M.K. Cooper, L.E. Mitchell, K. Henrick, M. McPartlin, A. Scott, Inorg. Chim. Acta, 1984, 84, L9

50 R. Uson, A. Laguna, M. Laguna, E. Fernandez, M.D. Villacampa, P.G. Jones, G.M. Sheldrick, J. Chem. Soc. Dalton Trans., 1983, 1679

51 H. Schmidbaur, C. Paschalidis, O. Steigelmann, G. Müller, Chem. Ber., 1989, 122, I851

52 P.G. Jones, Acta Crystallogr., B, 1980, 36, 2775

53 Ref. 5, p. $1033 \mathrm{ff}$.

54 H. Schmidbaur, W. Graf, G. Müller, Helv. Chim. Acta, 1986, 69, 1748; Angew. Chem., 1988, 100, 439; Angew. Chem. Int. Ed. Engl., 1988, 27, 417

55 H. Schmidbaur, K. Dziwok, A. Grohmann, G. Müller, Chem. Ber., 1989, 122, 893

56 K. Dziwok, J. Lachmann, G. Müller, H. Schmidbaur, Chem. Ber., in press

57 Y. Kai, P. Knochel, S. Kwiatkowski, J. D. Dunitz, J.F.M. Oth, D. Seebach, H.O. Kalinowski, Helv. Chim. Acta, 1982, 65, 137

58 H. Schmidbaur, A. Wohlleben, U. Schubert, G. Huttner, Chem. Ber., 1977, 110, 2751

59 M.N.I. Khan, C. King, D.D. Heinrich, J.P. Fackler, L.C. Porter, Inorg. Chem., 1989, 28, 2150

60 J.D. Basil, H.H. Murray, J.P. Fackler, J. Tocher, A.M. Manany, B.T. Bancroft, H. Knachel, D. Dudis, T.J. Delord, D.O. Marler, J. Amer. Chem. Soc., $1985,107,6908$

61 H. Schmidbaur, R. Franke, Inorg. Chim. Acta, 1975, 13, 81

62 H. Schmidbaur, J.R. Mandl, W. Richter, V. Bejenke, A. Frank, G. Huttner, Chem. Ber, 1977, 110, 2236

63 H. Schmidbaur, H.P. Scherm, U. Schubert, ibid, 1978, 111, 764

64 H. Schmidbaur, T. Pollok, R. Herr, F.E. Wagner, R. Bau, J. Riede, G. Müller, Organometallics, 1986, 5, 566

65 H. Schmidbaur, T. Pollok, G. Reber, G. Müller, Chem. Ber., 1988, 121, 1345

66 A. Müller, H. Dornfield, G. Henkel, B. Krebs, M.P.A. Viegers, Angew. Chem., 1978, 90, 57; Angew. Chem. Int. Ed. Engl., 1978, 17, 52

67 C. L. Teske, Z. Anorg. Allg. Chem., 1978, 445, 193

68 M.N.I. Khan, J.P. Fackler, C. King, J.C. Wang, S. Wang, Inorg. Chem., 1988, 27, 1673; O. Piovesana, P.F. Zanazzi, Angew. Chem., 1980, 92, 577; Angew. Chem. Int. Ed. Engl., 1980, 19, 561 
69 Y. Inoguchi, B. Milewski-Mahrla, H. Schmidbaur, Chem. Ber, 1982, 115, 3085

70 H. Schmidbaur, J.R. Mandl, J.M. Bassett, G. Blaschke, B. Zimmer-Gasser, Chem. Ber., 1981, 114, 433

71 C.E. Briant, K.P. Hall, D.M.P. Mingos, J. Organometal. Chem., 1982, 229, C5

72 W. Ludwig, W. Meyer, Hely. Chim. Acta, 1982, 65, 934

73 H.-R.C. Jaw, M.M. Savas, R.D. Rogers, W.R. Mason, Inorg. Chem., 1989, 28, 1028

74 C. King, J.-Ch. Wang, M.N.I. Khan, J.P. Fackler Jr., Inorg. Chem., 1989, 28, 2145

75 J. Ebner v. Eschenbach, O. Kumberger, G. Müller, H. Schmidbaur, Chem. Ber., in press

76 a) A. Müller, M. Römer, H. Bögge, E. Krickmeyer, K. Schmitz, Inorg. Chim. Acta, 1984, 85, L39. b) W.S. Krane, H. Beall, Inorg. Chim. Acta, 1978, 31, LA69

77 V.G. Andrianov, Y.T. Struchkov, E.R. Rossinskaya, Zh. Strukt. Khim. 1974, 15, 74; Engl. Transl.: p. 65.

78 T.V. Baukova, Y.L. Shlovokhotov, Y.T. Struchkov, J. Organometal. Chem., 1981, 220, 375

79 E.G. Perevalova, K.I. Grandberg, T.V. Baukova, V.P. Dyadchenko, Y.L. Shlovokhotov, Y.T. Struchkov, Koord. Khim., 1982, 8, 1337

80 H. Schmidbaur, Y. Inoguchi, Chem. Ber., 1980, 113, 1646 and refs. therein

81 S. Gambarotta, C. Floriani, A. Chiesi-Villa, C. Guastini, J. Chem. Soc. Chem. Commun., 1983, 1304

82 J. Vicente, M.T. Chicote, J.A. Cayuelas, J. FernandezBaeza, P.G. Jones, G.M. Sheldrick, P. Espinet, J. Chem. Soc., Dalton Trans., 1985, 1163

83 H. Schmidbaur, F. Scherbaum, B. Huber, G. Müller, Angew. Chem., 1988, 100, 441; Angew. Chem. Int. Ed. Engl., 1988, 27, 419

84 E.I. Smyslova, E.G. Perevalova, V.P. Dyadchenko, K.I. Grandberg, Y.L. Shlovokhotov, Y.T. Struchkov, J. Organometal. Chem., 1981, 215, 269

85 A.N. Nesmeyanov, G.G. Perevalova, Y.T. Struchkov, M.Y. Antipin, K.I. Grandberg, V.P. Dyadchenko, J. Organometal. Chem., 1980, 201, 343

86 C. Lensch, P.G. Jones, G.M. Sheldrick, Z. Naturforsch., B, 1982, 37, 944; P.G. Jones, C. Lensch, G.M. Sheldrick, ibid., 141

87 G. Marbach, J. Strähle, Angew. Chem., 1984, 96, 695; Angew. Chem. Int., Ed. Engl. 1984, 23, 715

88 C.E. Briant, K.P. Hall, A.C. Wheeler, D.M.P. Mingos, J. Chem, Soc. Chem. Commum, 1984, 248

89 P.G. Jones, G.M. Sheldrick, E. Hädicke, Acta Crystallogr, 1980, B 36, 2777

90 Y.L. Shlovokhotov, Y.T. Struchkov, J. Organometal. Chem., 1984, 277, 143
91 Diss. W. Kreß, Univ. Erlangen-Nürnberg, 1983

92 P.G. Jones, G.M. Sheldrick, R. Uson, A. Laguna, Acta Crystallogr., B, 1980, 36, 1486

93 H. Schmidbaur, F. Scherbaum, B. Huber, G. Müller, Angew. Chem., 1988, 100, 441; Angew. Chem. Int. Ed. Engl., 1988, 27, 419

94 F. Scherbaum, B. Huber, G. Müller, H. Schmidbaur, Angew. Chem., 1988, 100, 1600; Angew. Chem. Int. Ed. Engl., 1988, 27, 1542

95 F. Scherbaum, A. Grohmann, B. Huber, C. Krüger, H. Schmidbaur, Angew. Chem., 1988, 100, 1602; Angew. Chem. Int. Ed. Engl., 1988, 27, 1544

96 F. Scherbaum, A. Grohmann, G. Müller, H. Schmidbaur, Angew. Chem. 1989, 101, 464; Angew. Chem. Int., Ed. Engl., 1989, 28, 463

97 J.J. Steggerda, J.J. Bour, J.W.A. van der Velden, Recl. Trav. Chim. Pays-Bas, 1982, 101, 164

98 C.E. Briant, K.P. Hall, D.M.P. Mingos, J. Organometal. Chem, 1983, 254, C 18

99 P.L. Bellon, F. Cariati, Manaserro, L. Naldini, M. Sansoni, Chem. Commun., 1971, 1432; P.L. Bellon, M. Manaserro, M. Sansoni, J. Chem. Soc. Chem. Commun., 1972, 1035

100 H. Schmidbaur, A. Grohmann, unpubl. results, 1989

101 a) R. Uson, A. Laguna, M. Laguna, M.T. Tarton, P.G. Jones, J. Chem. Soc. Chem. Commun., 1988, 740 ;

b) H. Schmidbaur, C. Hartmann, G. Reber, G. Müller, Angew. Chem., 1987, 99, 1189; Angew. Chem. Int., Ed. Engl., 1987, 26, 1146; c) R.G. Raptis, J.P. Fackler, H.H. Murray, L.C. Porter, Inorg. Chem., in press

102 H.H. Murray, D.A. Briggs, G. Garzon, R.G. Raptis, L.C. Porter, J.P. Fackler, Organometallics, 1987, 6, 1992

103 S. Wang, J.P. Fackler, Organometallics, 1988, 7, 2415; 1989, 8, 1578; S. Wang, J.P. Fackler, C. King, J.C. Wang, J. Amer. Chem. Soc. 1988, 110, 3308; C. King, D.D. Heinrich, G. Garzon, J.-C. Wang, J.P. Fackler, J. Amer, Chem. Soc. 1989, 111, 2300

104 A.L. Balch, J.K. Nagle, M.M. Olmstaedt, P.E. Reedy, J. Amer: Chem. Soc., 1987, 109, 4123; J.K. Nagle, A.L. Balch, M.M. Olmstaedt, ibid., 1988, 110, 319

105 Ref. $13 \mathrm{c}$, p. 48

106 See chapters on compounds with transition metal bonds to gold in ref. 13

107 P. Braunstein, J. Rosé, Gold Bull., 1985, 18, 17

108 M. Jansen, Angew. Chem., 1987, 99, 1136; Angew. Chem. Int., Ed. Engl., 1987, 27, 1098

109 W.S. Rapson, T. Groenewald 'Gold Usage', Academic Press, London, 1978 